\title{
ELECTROPOLISHING PROCEDURE DEDICATED TO IN-DEPTH STRESS MEASUREMENTS WITH X-RAY DIFFRACTOMETRY
}

\author{
Elżbieta Gadalińska \\ Wojciech Wronicz \\ Institute of Aviation, Materials and Structures Research Center, \\ Al. Krakowska 110/114, 02-256 Warsaw, Poland \\ elzbieta.gadalinska@ilot.edu.pl, wojciech.wronicz@ilot.edu.pl
}

\begin{abstract}
Electropolishing is the sole reliable method of removing the outer layer of the specimen without changing its stress state. This feature of the electropolishing procedure allows researchers to investigate the in-depth stress distribution. Developing of the method in a diffraction laboratory is crucial because there is no universal theory for the electropolishing procedure allowing the removal of the layers of different thickness. This is due to the multiplicity of different factors affecting the electropolishing results. A factor of vital importance from the point of view of indepth stress measurements is the thickness of the electropolishing layer. Hence the importance of the procedures for the electropolishing of a layer of a precisely defined thickness.

This work deals with the problem of the selection of the parameters in the electropolishing process for two types of materials: stainless steel and aluminium alloy. The tests of mutual correlation of current intensity, voltage applied and time of the procedure and its results are presented in the paper.
\end{abstract}

Keywords: In-Depth stress distribution, Electropolishing, Diffraction methods.

\section{INTRODUCTION}

\section{Electropolishing: its advantages and disadvantages}

In the electrolytic polishing procedure, which nowadays is very well recognized, the disposal of the outer layer of the material is performed by removing it ion by ion. Electropolishing was invented in 1929 by Pierre Jacquet and was used for the first time in 1935 in preparing metallographic sample. This technique can be used instead of many different types of surface treatment including milling, grinding, blasting and buffing. Electropolishing involves submerging the object into the electrolyte dedicated to the type of the material. Simultaneously, the object is subjected to an electrical current. During the electropolishing process, the object is maintained anodic. The phenomena accompanying electropolishing are the saturation of the surface with the dissolved metal and the rise of the temperature resulting the gassing effect.

The main advantage of electropolishing is the quality of the smooth surface created on the metal object is higher than if obtained by any method involving mechanical polishing. Additionally, from the in-depth stress measurement point of view (for example with X-ray diffraction methods) electropolishing neither disturbs the stress distribution nor introduces any additional values of stresses. The result of electropolishing is a surface without any defined microscopically features i.e. with neither torns nor pits: the surface becomes microscopically smooth, bright and clean. Electropolishing removes scratches and deformations due to cutting or 
grinding. Another advantage of electropolishing is the reduction of the friction coefficient value. Compared to the mechanically finished surface, the friction coefficient can be even $75 \%$ lower. Unfortunately, alongside the above advantages there are also drawbacks. The main disadvantage is associated with polishing multiphase alloys and composites due to different polishing rates of the ingredients.

The main difference between electropolishing and mechanical polishing is that the later always leaves smears, scratches, strains, metal debris and abrasives embedded in the surface of the object. Electropolishing unveils the crystal structure while finishing processes which abrasives employ always somehow deform and tamper with the metal surface: abrasives penetrates into the metal becoming inserted in the surface. The influence of the mechanical treatment can be very significant from the material strength point of view; for example the finishing operations of steel can lead to a threefold decrease in tensile strength.

The electropolishing procedure is not always easy to perform. Sometimes it is necessary to perform the initial treatment with abrasives before appropriate electrolytic polishing, especially when e.g. orange peel or mold surface texture are visible.

Although there is no universal, applicable procedure for electropolishing there are some indications for the sample preparation prior to electropolishing and some suggestions on parameters affecting electropolishing. Before electropolishing, the sample should be finished by mechanical polishing (600-grit). During electropolishing, the correct combination of bath temperature, voltage, current density, and time should be applied: the metallographer has to control many experimental variables.

\section{Theoretical background}

The first step in working out the electropolishing procedure for the material-electrolite sets is to prepare the curve for the relation: applied voltage versus current density. A typical curve of current density versus voltage is shown in Figure 1. It helps to establish the most appropriate current and voltage parameters in order to obtain best polishing results. Three stages can be observed. At the first stage, for low voltage values where the almost linear dependence (A-B) appears, etching occurs. The second stage (C-D) is the most interesting for the electropolisher as this is when electropolishing takes place. The last stage (D-E) for high voltages is the region of gas evolution and pitting. The optimal parameters for electropolishing are defined by point $\mathrm{C}$.

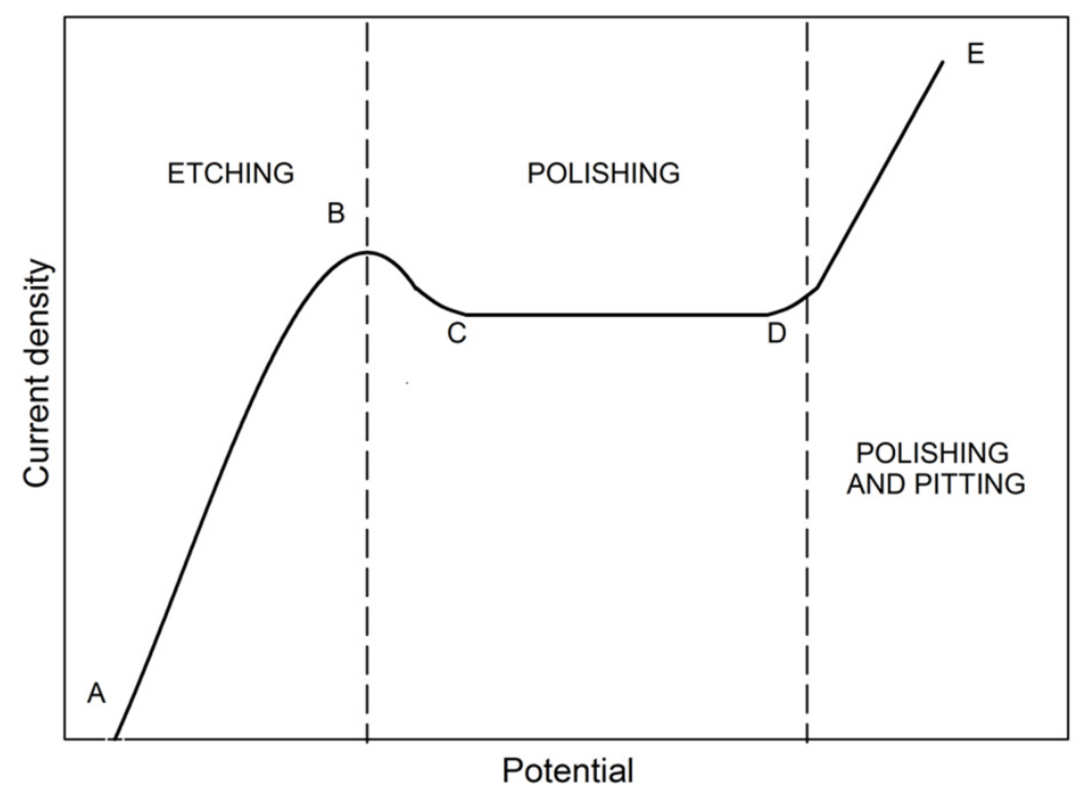

Fig. 1. The typical relation between current density versus voltage for electropolishing [2]. 
To delineate the current vs. voltage plot the cathode area should be much larger than the anode surface area. In this condition, liberation of hydrogen does not affect the shape of the curve. It is important remember that the shape of the curve depends on the processes occurring at the anode. Unfortunately, it was impossible to work out one universal theory of the electropolishing procedure due to too many independent variables affecting the process. Nevertheless, the solutions to typically occurring problems were developed and presented in ASTM Standard E3 [3], see table 1.

Table 1. Problems possible to occur during the electropolishing and its corrections [3].

\begin{tabular}{|c|c|c|}
\hline Trouble & Possible cause & Suggested solution \\
\hline $\begin{array}{l}\text { Center of the specimen deeply } \\
\text { etched }\end{array}$ & $\begin{array}{l}\text { No polishing film at the } \\
\text { center of the specimen }\end{array}$ & $\begin{array}{l}\text { - Increase voltage } \\
\text { - Decrease agitation } \\
\text { - Use more viscous electrolyte }\end{array}$ \\
\hline $\begin{array}{l}\text { Pitting or etching at edges of } \\
\text { specimen }\end{array}$ & Too viscous or thick film & $\begin{array}{l}\text { - Decrease voltage } \\
\text { - Increase agitation } \\
\text { - Use less viscous electrolyte }\end{array}$ \\
\hline Sludge settling on the surface & Insoluble anode product & $\begin{array}{l}\text { - } \text { Try new electrolyte } \\
\text { - Increase temperature } \\
\text { - Increase voltage }\end{array}$ \\
\hline Roughness or matte surface & $\begin{array}{l}\text { Insufficient or no polishing } \\
\text { film }\end{array}$ & $\begin{array}{l}\text { - Increase voltage } \\
\text { - Use more viscous electrolyte }\end{array}$ \\
\hline $\begin{array}{l}\text { Waviness or streaks on the } \\
\text { polished surface }\end{array}$ & $\begin{array}{l}\text { Insufficient time } \\
\text { Incorrect agitation } \\
\text { Inadequate preparation } \\
\text { Too long time }\end{array}$ & $\begin{array}{l}\text { - Increase or decrease agitation } \\
\text { - Use better preparation } \\
\text { - Increase voltage or decrease } \\
\text { time }\end{array}$ \\
\hline Stains on polished surface & $\begin{array}{l}\text { Attack after polishing } \\
\text { current is off }\end{array}$ & $\begin{array}{l}\text { - Remove specimen while current } \\
\text { is still on } \\
\text { - Try less corrosive electrolyte }\end{array}$ \\
\hline Unpolished spots (bullseyes) & Gas bubbles & $\begin{array}{l}\text { - Increase agitation } \\
\text { - Decrease voltage }\end{array}$ \\
\hline Phases in relief & Insufficient polishing film & $\begin{array}{l}\text { - Increase voltage } \\
\text { - Use better preparation } \\
\text { - Decrease time }\end{array}$ \\
\hline Pitting & $\begin{array}{l}\text { Polishing too long } \\
\text { Voltage too high }\end{array}$ & $\begin{array}{l}\text { - Use better preparation } \\
\text { - Decrease voltage } \\
\text { - Decrease time } \\
\text { - } \text { Try different electrolyte }\end{array}$ \\
\hline
\end{tabular}

The most important factor from the electropolishing procedure point of view is the rise of temperature, which causes the subsequent phenomena: a decrease in the electrolyte resistance, the plateau current density decrease, the bath viscosity decrease (making it more difficult to maintain a viscous anode layer) and, in consequence, the deterioration of the surface quality. Naturally, both the type of the electropolished material and the type of the electrolyte affect the time needed to remove a layer of a desired thickness: generally the higher the plateau current density, the shorter time is needed. It is worth to notice that long electropolishing times can result in some undesirable artifacts such as surface waviness and relief accentuation. 


\section{EXPERIMENT}

\section{Material and specimens}

The materials chosen for the experiment were: stainless steel 1H13 and aluminium alloy 2024 .

$1 \mathrm{H} 13$ stainless steel is a semi-ferritic steel used in valves, hydraulic presses, steam turbine blades and nuts production. Its chemical composition and some physical properties are presented in tables 2 and 3.

\section{Table 2. Different standards designations for $1 \mathrm{H} 13$ martensitic stainless steel} and its chemical composition.

\begin{tabular}{|l|l|l|c|}
\hline \multicolumn{2}{|c|}{$\begin{array}{c}\text { Other standards } \\
\text { designations }\end{array}$} & \multicolumn{2}{c|}{$\begin{array}{c}\text { Chemical composition } \\
{[\%]}\end{array}$} \\
\hline EN & 1.4006 & $\mathrm{C}$ & $0,08-0,15$ \\
\hline DIN & X12Cr13 & $\mathrm{Cr}$ & $11,50-13,50$ \\
\hline AISI & 410 & $\mathrm{Si}$ & $\leq 1,00$ \\
\hline Russia & $12 \mathrm{Ch} 13$ & $\mathrm{Mn}$ & $\leq 1,50$ \\
\hline Others & 2302 & $\mathrm{Ni}$ & $\leq 0,75$ \\
& $1 \mathrm{Cr} 12$ & & $\leq 0,015$ \\
\hline \multirow{2}{*}{} & $\mathrm{S}$ & $\leq 0,040$ \\
\cline { 2 - 3 } & $\mathrm{P}$ & \\
\cline { 2 - 3 } &
\end{tabular}

Table 3. Mechanical and physical properties of 1 H13 stainless steel.

\begin{tabular}{|c|c|c|c|}
\hline \multicolumn{2}{|c|}{ Mechanical properties } & \multicolumn{2}{|c|}{ Physical properties } \\
\hline$R_{m}$ & $700-850 \mathrm{MPa}$ & density at $20^{\circ} \mathrm{C}$ & $7,7 \mathrm{~kg} / \mathrm{dm}^{3}$ \\
\hline$R_{e}$ & $450-500 \mathrm{MPa}$ & E & $215 G P a$ \\
\hline $\begin{array}{l}\text { percentage elongation } \\
\text { after fracture }\end{array}$ & $20 \%$ & \multirow[t]{2}{*}{$\begin{array}{l}\text { thermal expansion } \\
\text { coefficients }\end{array}$} & $20^{\circ} \mathrm{C}-200^{\circ} \mathrm{C}: 11 \cdot 10^{-6} \mathrm{~K}^{-1}$ \\
\hline \multicolumn{2}{|c|}{ hardness } & & $200^{\circ} \mathrm{C}-400^{\circ} \mathrm{C}: 12 \cdot 10^{-6} \mathrm{~K}^{-1}$ \\
\hline $\begin{array}{l}\text { hardened and } \\
\text { tempered }\end{array}$ & $\geq 24 H R C$ & $\begin{array}{l}\text { coefficient in thermal } \\
\text { conductivity }\end{array}$ & $30 W /(m K)$ \\
\hline softened state & $220 H B$ & specific heat at $20^{\circ} \mathrm{C}$ & $460 \mathrm{~J} /(\mathrm{kg} \cdot \mathrm{K})$ \\
\hline & & resistivity & $0,6\left(\Omega \cdot \mathrm{mm}^{2}\right) / \mathrm{m}$ \\
\hline
\end{tabular}

The second investigated material was 2024-T3 aluminium alloy, which is characterized by good machinability and surface finish capabilities. This alloy is used in aircraft fittings, gears and shafts, bolts, clock parts, computer parts, couplings, fuse parts, hydraulic valve bodies, missile parts, munitions, nuts, pistons, rectifier parts, worm gears, fastening devices, veterinary and orthopedic equipment and structures. 
Table 4. Different standards designations for aluminium alloy 2024T3 and its chemical composition.

\begin{tabular}{|l|l|l|c|}
\hline \multicolumn{2}{|c|}{$\begin{array}{c}\text { Other standards } \\
\text { designations }\end{array}$} & \multicolumn{2}{c|}{$\begin{array}{c}\text { Chemical composition } \\
{[\%] ~}\end{array}$} \\
\hline $\begin{array}{l}\text { EN } \\
\text { ASTM }\end{array}$ & 2024 & $\mathrm{Si}$ & $\leq 0,5$ \\
\hline DIN & $\begin{array}{l}\mathrm{AlCu} 4 \mathrm{Mg} 1 \\
\mathrm{AlCu} 4 \mathrm{Mg} 2\end{array}$ & $\mathrm{Fe}$ & $\leq 0,5$ \\
\hline \multirow{2}{*}{ Russia } & 1160 & $\mathrm{Cu}$ & $3,8-4,9$ \\
& $\mathrm{D} 16$ & $\mathrm{Mn}$ & $0,3-0,9$ \\
\cline { 3 - 4 } & $\mathrm{Mg}$ & $1,2-1,8$ \\
\cline { 3 - 4 } & $\mathrm{Cr}$ & $\leq 0,1$ \\
\cline { 3 - 4 } & $\mathrm{Zn}$ & $\leq 0,25$ \\
\cline { 3 - 4 } & $\mathrm{Ti}$ & $\leq 0,15$ \\
\cline { 3 - 4 } & $\mathrm{Zr}$ & $\leq 0,1$ \\
\cline { 3 - 4 } & &
\end{tabular}

Table 5. Mechanical and physical properties of $2024 T 3$ aluminum alloy.

\begin{tabular}{|l|c|l|c|}
\hline \multicolumn{2}{|c|}{ Mechanical properties } & \multicolumn{2}{c|}{ Physical properties } \\
\hline \multicolumn{1}{|c|}{$R_{m}$} & $360-435 \mathrm{MPa}$ & density in $20^{\circ} \mathrm{C}$ & $2,78 \mathrm{~kg} / \mathrm{dm}^{3}$ \\
\hline$R_{e}$ & $250-290 \mathrm{MPa}$ & $\mathrm{E}$ & $230 \mathrm{GPa}$ \\
\hline $\begin{array}{l}\text { percentage elongation } \\
\text { after fracture }\end{array}$ & $12 \%-14 \%$ & $\begin{array}{l}\text { thermal expansion } \\
\text { coefficients }\end{array}$ & $121 \mathrm{Wm} / \mathrm{mK}$ \\
\hline hardness & $104-123$ & $\begin{array}{l}\text { coefficient in thermal } \\
\text { conductivity }\end{array}$ \\
\cline { 2 - 4 } & specific heat at $20^{\circ} \mathrm{C}$ & $874 \mathrm{~J} / \mathrm{kg} \cdot \mathrm{K})$ \\
\cline { 2 - 4 }
\end{tabular}

1H13 stainless steel was mechanically polished and 2024T3 aluminium alloy specimen was a sheet of metal as delivered.

\section{The equipment and electrolyte used during the experiment}

The equipment used for the experiment was the mobile polisher and etcher dedicated to the local outer layer removal, KR650 by ATM Company (Fig. 2). It allowed operators' to perform electropolishing only in the chosen area in where the stress state was known.

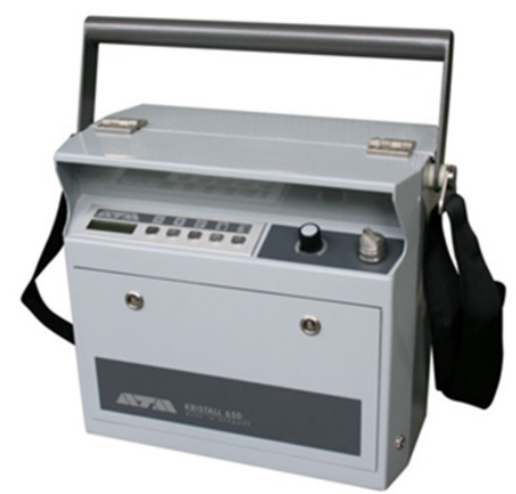

Fig. 2. KR650 mobile electropolisher. 
Electropolishing is performed by the head with a long house providing the electrolyte and being the cathode. Polishing and etching gets automatically ready by touching the piezo button at the handle. The equipment enables electropolishing even on an area of $9 \mathrm{~mm}$ in diameter and on complex surfaces with curvature. The flow of electrolyte voltage, current intensity and time can be regulated. The power available is $160 \mathrm{~W}$ and the range of voltage is $90 \mathrm{~V}$ DC while the maximum current value is $2 \mathrm{~A}$.

The electrolyte used during the experiment was the K1 electrolyte dedicated to all steel types, alluminium and its alloys, nickel, tin, and titanium. K1 electrolyte is a mixture of perchloric acid, ethanol and Propandiol-1,2.

\section{Plateau region determination}

Prior to conducting the main part of the experiment (determining the relationship between time of electropolishing and the thickness of electropolished layer), the electropolishing parameters had to be determined. In order to do so, electropolishing was performed for both materials. The voltage value was a variable during the experiment and the current intensity was the measured value. The results are presented in Figures 3 and 4.

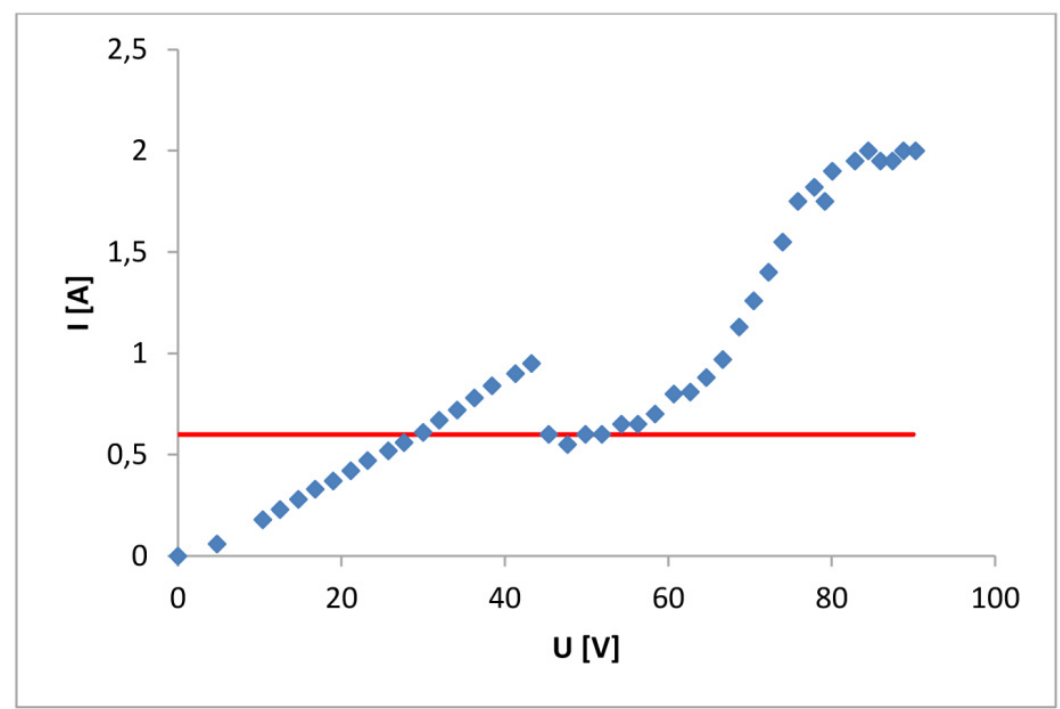

Fig. 3. The I-U characteristic during electropolishing for stainless steel $1 H 13$.

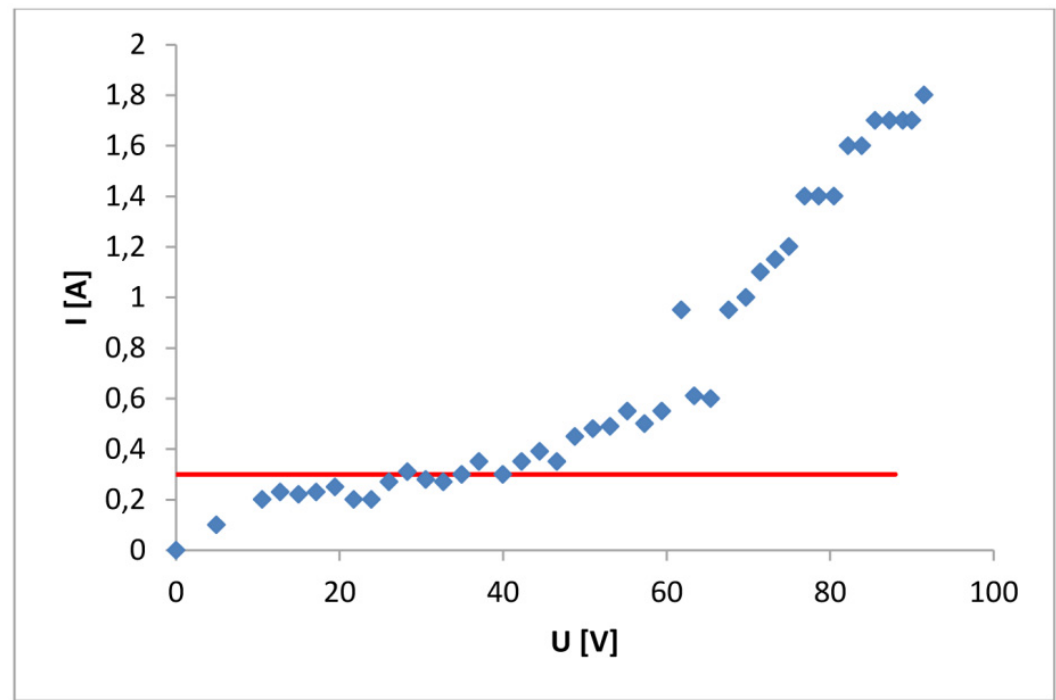

Fig. 4. The I-U characteristic during electropolishing for $2024 T 3$ aluminium alloy. 
The plateau region of the above plots was selected as $0,6 \mathrm{~A}$ for the chosen type of steel and 0,3A for aluminium alloy 2024T3. For these current values, the electropolishing process should be performed in an optimal way.

\section{Electropolished depth vs. time relationships}

The relationship between the thickness of the electropolished layer and the duration of the process is crucial for in depth stress measurements. The linear relatonship between these values was assumed. The measurement was performed once for both materials in the time range of $300 \mathrm{~s}$. For stainless steel, the optimal current value was set i.e. 0,6A and the time interval was 30s in the time range $0-120 \mathrm{~s}$, while above $120 \mathrm{~s}$ the time interval was $15 \mathrm{~s}$. For aluminium alloy the optimal current value was twice lower (i.e. $0,3 \mathrm{~A}$ ) and the time interval was $10 \mathrm{~s}$ for values $0-240 \mathrm{~s}$, the additional electropolishing was performed for the time of 300 s.

Selected electropolished surfaces are presented in Figure 5.

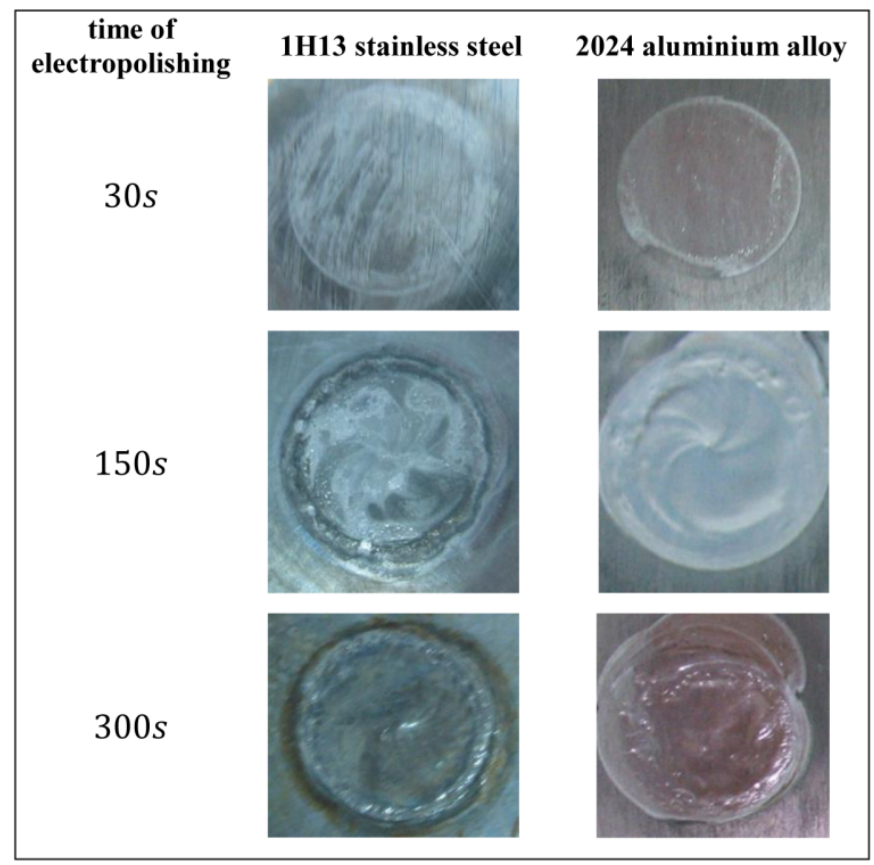

Fig. 5. Surface after electropolishing.

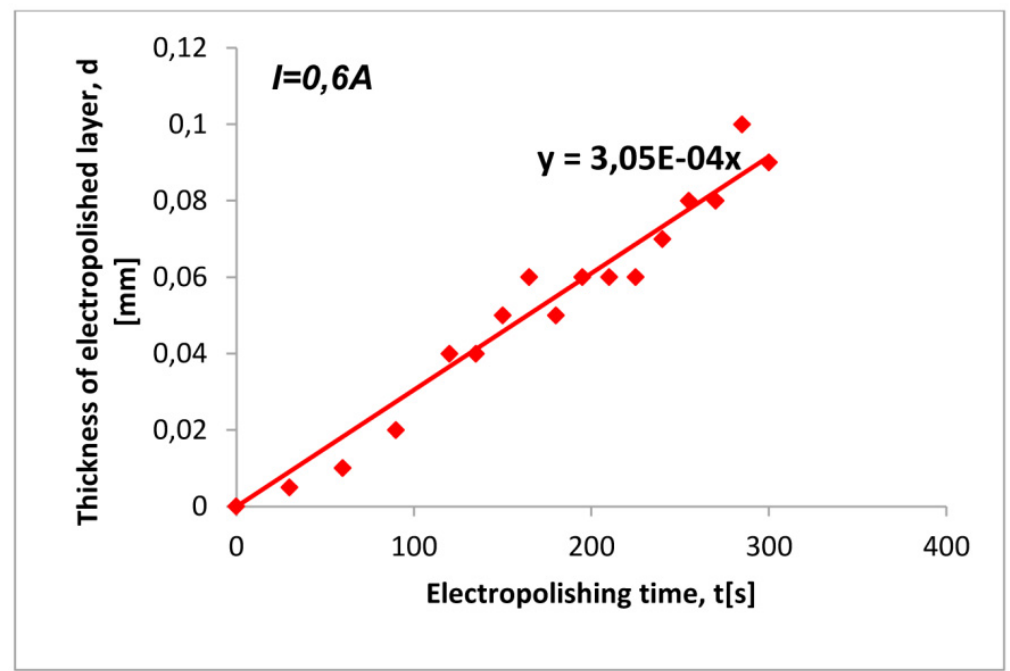

Fig. 6. Electropolished layer thickness versus electropolishing time for stainless steel 1 H13. Current for electropolishing process was $I=0,6 \mathrm{~A}$. 


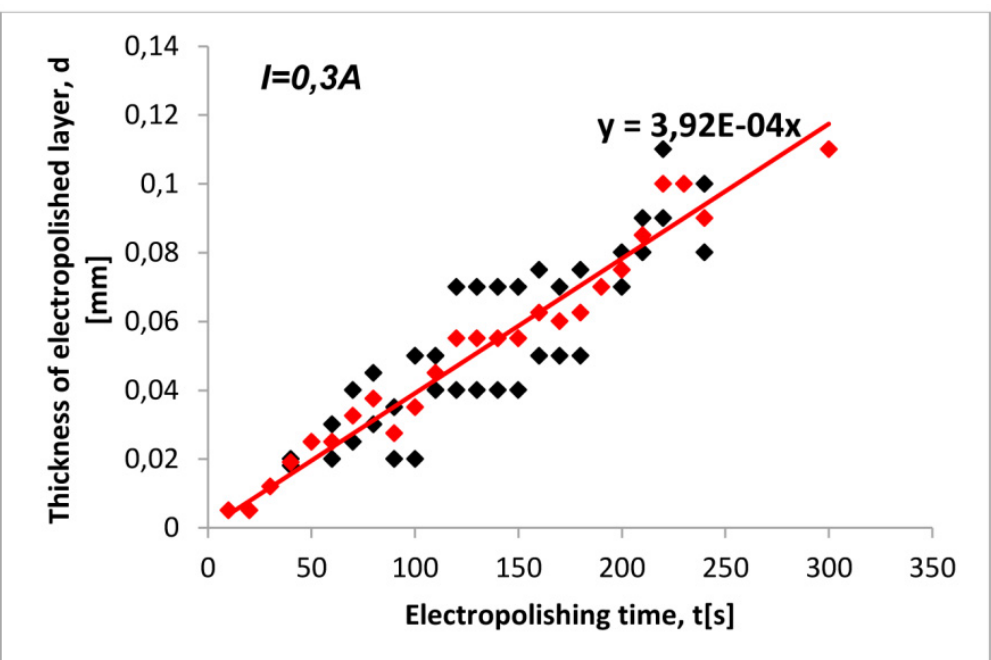

Fig. 7. Electropolished layer thickness versus electropolishing time for aluminium alloy 2024T3. Current for electropolishing process was $I=0,6 \mathrm{~A}$.

The electropolished layer thickness measurements were performed with a depth sensor whose accuracy was $0,01 \mathrm{~mm}$. The results are presented in Figures 6 and 7.

The measurement points were approximated by linear dependency: the slope for the steel was $3,05 \cdot 10^{-4}$ and for aluminum alloy: $3,92 \cdot 10^{-4}$. The plots allow determining the time values necessary to electropolish the needed layer. Additionally it allows predicting the time values for deeper electropolishing by extrapolating the obtained plot. To remove a layer of $0,1 \mathrm{~m}$ of $1 \mathrm{H} 13$ steel, the electropolishing procedure should last about 33s, while for $2024 \mathrm{~T} 3$ aluminium alloy it is $25 \mathrm{~s}$.

\section{CONCLUSIONS}

Voltage-current characteristics for the electropolishing process were obtained for two materials: $1 \mathrm{H} 13$ stainless steel and 2024T3 aluminium alloy. This allowed researchers to choose the optimal parameters for the electropolishing procedure. The relation between depth and duration of electropolishing was determined. This would allow the removal of a very precisely defined layer for e.g in-depth diffraction stress measurements. It was also concluded that with a thick layer (e.g. $0,1 \mathrm{~mm}$ ) it is better to perform electropolishing incrementally rather than for a long time at one go (300s). As Figure 5 shows, the surface of the area electropolished for a relatively shorter time is smoother than those surfaces electropolished longer. Moreover, incremental electropolishing allows a better controll of the specimen and electrolyte's temperature.

\section{REFERENCES}

[1] https://www.delstar.com/

[2] Vander Voort G.F. (1999). Metalography. Principles and Practice, ASM International.

[3] American Society for Testing and Materials Standard E3, "Standard Methods of Preparation of Metallographic Specimens"

[4] http://www.sebros.eu/ 